\title{
INKUBATOR BISNIS SEBAGAI PENDORONG TUMBUHNYA WIRAUSAHA MUDA: STUDI TENTANG SUKSESI KEWIRAUSAHAAN MAHASISWA UNIVERSITAS MUHAMMADIYAH GRESIK
}

\author{
Beni Dwi Komara \\ Progran Studi Kewirausahaan, Fakultas Ekonomi dan Bisnis, Universitas Muhammadiyah Gresik \\ benikomara@umg.ac.id
}

\section{Heri Cahyo Bagus Setiawan}

Progran Studi Kewirausahaan, Fakultas Ekonomi dan Bisnis, Universitas Muhammadiyah Gresik hericbs@umg.ac.id

\begin{abstract}
The Entrepreneurship study program of the University of Muhammadiyah Gresik has succeeded in encouraging the growth of young entrepreneurs as evidenced by $66 \%$ of students having their own businesses and $86 \%$ of students having experience of failing to start a business. Further research needs to be carried out on how the key to success of students having a business since they were in college and knowing how to enhance the role of business incubators at the University as a driver of growth in young entrepreneurs. The study used this qualitative method by collecting data from indepth interviews with entrepreneurial study program students who had a business of 23 people, 6 teaching lecturers, Head of Laboratory \& Business Incubation Center and Head of Entrepreneurship Study Program. Then a focus group discussion (FGD) is conducted. The results of this study indicate that the success of students having their own business was determined by strong interest \& motivation to have their own business, the ability to make business plans, work hard so that they have the courage to fail in starting a business, knowledge \& skills shown by having attended entrepreneurship training and the existence of family \& environment support such as campus. Many universities play a role in spurring the creation of young entrepreneurs on campus including by providing services for initial product development, improving business quality, providing training to improve skills, mentoring and providing access to capital for student businesses. But as a business incubator the University is still not optimal and needs to be improved in terms of Shared that is not yet providing office facilities that can be used together and Synergy, which is not yet created tenant cooperation or competition between tenants and networks with universities, research institutes, private businesses, professionally and with the international community.
\end{abstract}

Keywords : Business, Entrepreneurship, Young Entrepreneurs, business incubators

\section{PENDAHULUAN}

Indonesia tidak hanya kekurangan pengusaha namun juga pengusaha muda, sesuai disampaikan oleh Menteri Pemuda dan Olahraga (Menpora) Imam Nahrawi pada Kamis (27/7/2017). "Indonesia kekurangan pengusaha muda. Jika dibandingkan jumlah pemuda ada sekitar 61 juta sementara pengusaha hanya 1,5 juta. Idealnya kita punya 20 juta pengusaha muda," saat pembukaan Workshop penumbuhan minat berwirausaha pemuda di kampus Universitas Muhammadiyah (Ispranoto,2017). Selanjutnya perlu dilakukan upaya agar jumlah wirausahawan atau pengusaha semakin bertambah, oleh karena itu perlu dilakukan upaya nyata agar jumlah pengusaha terus bertambah. Prodi Kewirausahaan Fakultas Bisnis \& Ekonomi Universitas Muhammadiyah Gresik sudah melakukan pembinaan selama 3 tahun untuk berusaha menjawab tantangan membentuk pengusaha di usia muda. Program Studi Kewirausahaan Fakultas Ekonomi \& Bisnis Universitas Muhammadiyah Gresik ini jenjang pendidikan Strata 1, dengan VISI menjadi 
program studi yang menghasilkan wirausaha berdaya saing tinggi dan unggul berdasarkan nilai-nilai ke-Islaman tahun 2026. MISI, Menyelenggarakan pendidikan kewirausahaan yang berkualitas, inovatif, berlandaskan nilai-nilai ke-Islaman. Membangun kemitraan dengan stakeholder baik secara regional, maupun nasional untuk mengembangkan ekonomi kreatif Indonesia.

Profil Lulusan Program Studi adalah membentuk Wirausaha Muda, Perencana Bisnis, Konsultan Bisnis, dan Pengembang Bisnis. www.umg.c.id). Kekuatan Prodi Kewirausahaan ada pada 3 hal yakni Kurikulum yang telah mengadopsi kebutuhan untuk menjadi seorang pengusaha, dosen pengajar yang berimbang antar dosen berlatar belakang akademis dan dosen dari kalangan praktisi pengusaha, dan adanya Laboratorium \& Pusat Inkubasi Bisnis sebagai tempat untuk mahasiswa melakukan praktikum melatih keterampilan kewirausahaan.

Hasil penelitian sebelumnya menunjukkan bahwa program studi Kewirausahaan berhasil membentuk pengusaha muda dibuktikan dengan terdapat $66 \%$ mahasiswa telah memiliki usaha sendiri dan terdapat $86 \%$ mahasiswa telah memiliki pengalaman memulai usahanya (Komara, B.D. and Kurniawan, A., 2020). Selanjutnya perlu dilakukan penelitian tentang bagaimana kunci sukses mahasiswa memiliki bisnis sejak masih kuliah dan mengetahui cara meningkatkan peran inkubator bisnis di Universitas sebagai pendorong tumbuhnya wirausahawan muda.

\section{METODE PENELITIAN \\ Indepth Interview}

Penelitian menggunakan metode kualitatif ini dengan pengumpulan data hasil wawancara mendalam dengan mahasiswa program studi kewirausahaan sejumlah 23 orang yang telah memiliki usaha, 6 orang dosen pengajar, Ketua Laboratorium \& Pusat Inkubasi Bisnis dan
Ketua Program Studi Kewirausahaan. Para informan tersebut, dirasa mewakili untuk menjawab kebutuhan riset ini. Selanjutnya dilakukan diskusi kelompok terarah (FGD) dengan mengundang mahasiswa dan dosen pengajar untuk mendiskusikan sesuai tujuan penelitian.

Dalam melakukan wawancara dalam riset ini, peneliti mendengarkan secara teliti dan mencatat apa yang dikemukakan oleh informan (Sugiyono, 2009).

\section{Focus Group Discussion (FGD)}

Selain melakukan indepth interview, riset ini juga melakukan Focus Group Disscusion (FGD). Menurut Irwanto (2006) Focus Group Disscusion (FGD) merupakan suatu proses pengumpulan data dan informasi yang sistematis mengenai suatu permasalahan tertentu yang sangat spesifik melalui diskusi kelompok. Sebagaimana makna dari FGD maka terdapat 3 kata kunci (Irwanto, 2005), yaitu:

1. Diskusi bukan wawancara atau obrolan

2. Kelompok bukan individual

3. Terfokus bukan bebas.

\section{Teknik Analisis}

Teknik analisis pada penelitian ini menggunakan:

1. Rekaman. Peneliti merekam keseluruan isi pembicaaraan antara pihak peneliti dengan informan.

2. Hasil rekaman tersebut ditranskip

3. Membahas dan menganalisa setiap kutipan yang berhubungan dengan konten bahasan penelitian dengan bantuan lampiran hasil transkip.

\section{Trianggulasi}

Riset ini menggunakan trianggulasi sumber. Sumber yang didapatkan ialah hasil dari wawancara mendalam (indepth interview) dan diskusi kelompok (FGD) di program studi kewirausahaan. Informan terdiri dari mahasiswa program studi kewirausahaan, dosen pengajar, Ketua Laboratorium \& Pusat Inkubasi Bisnis dan Ketua Program Studi Kewirausahaan.

\section{HASIL DAN PEMBAHASAN}




\section{Kunci Sukses Mahasiswa Berhasil Memiliki Bisnis Sendiri}

Analisis dan pembahasan dalam riset ini akan dipaparkan sebuah tentang bagaimana kunci sukses mahasiswa memiliki bisnis sendiri, yang ternyata diantaranya ditentukan oleh :

\section{Minat dan Motivasi Memiliki Usaha Sendiri}

Mahasiswa yang berhasil memiliki usaha sendiri tergolong memiliki minat yang sangat kuat yang ditunjukkan dari sikap mereka selalu antusias untuk belajar tentang hal baru di dunia usaha dan selalu siap untuk membukabisnis baru. Seperti diungkapkan oleh mahasiswa Alwi 19 tahun, "Saya sangat berminat mengikuti kegiatan kewirausahaan yang mendorong saya memiliki kesempatan untuk membuka usaha baru."

Bahwa minat dipengaruhi secara positif oleh sikap berperilaku, artinya bahwa semakin kuat (positif) penilaian individu terhadap baik tidaknya dampak menjadi wirausaha akan memperkuat keinginan individu tersebut untuk bekerja mandiri (self-employed) atau menjalankan usahanya sendiri. Dalam hal ini, semakin kuat sikap terhadap wirausaha, maka semakin kuat pula minat untuk menjadi wirausaha. Jackson dan Rodkey (1994) dalam Akmaliah dan Hisyamuddin (2009)

Dalam penelitian ditemukan beberapa motivasi mahasiswa dalam memiiki usaha sendiri, sesuai penjelasan tabel berikut ini :

\begin{tabular}{|c|l|}
\hline Jenis Motivasi & \% \\
\hline Realisasi Diri & $60 \%$ \\
\hline $\begin{array}{c}\text { Ambisi } \\
\text { Kemandirian }\end{array}$ & $35 \%$ \\
\hline Faktor Pendorong & $5 \%$ \\
\hline
\end{tabular}

Mahasiswa Sufatun Nisa 20 tahun,"

Saya ingin berhasil wirausaha demi meneruskan usaha orang tua." dan dikatakan mahasiswa Muhammad Faishal 19 tahun,"Semoga usaha saya bisa besar karena saya ingin membuka lapangan kerja dan ingin membantu orang lain."

Motivasi menjadi wirausaha didefinisikan sebagai adalah sesuatu yang melatarbelakangi atau mendorong seseorang melakukan aktivitas dan member energi yang mengarah pada pencapaian kebutuhan, member kepuasan ataupun mengurangi ketidakseimbangan dengan membuka suatu usaha atau bisnis. Menurut Zimmerer, 2002 dalam Venesar, 2006, bahwa motivasi seseorang menjadi wirausaha dibedakan dalam tiga, yaitu ambisi kemandirian, realisasi diri dan faktor pendorong.

\section{Kemampuan Membuat Perencanaan Usaha}

Terdapat $13 \%$ orang mahasiswa pemilik bisnis, yang tidak pernah membuat bisnis plan. Sisanya $87 \%$ mereka telah berpengalaman membuat dan mengimplementasikannya. Demikian disampaikan oleh mahasiswa Indika Affa Annaufal 21 tahun," Berulang kali saya buat bisnis plan, seringkali prakteknya jauh dari perencanaan karena banyak sekali hal-hal yang diluar perkiraan saya. Tapi tetap saya buat perencanaan bisnis agar mempermudah saya mencapai tahapan usaha yang saya rencanakan." dan dikatakan mahasiswa Nurus Sa'adah 20 tahun,"Selama ini saya belum menggunakan bisnis plan, mungkin saat ini masih terlalu ribet. Bagi saya saat ini yang penting buka usaha dulu yang trending, buat pengalaman bisnis saja. Suatu saat kalau pengetahuan, keterampilan dan modal yang digunakan besar baru saya akan teliti membuat perencanaan bisnis agar resiko gagal makin kecil ".

Bisnis Plan adalah dokumen tertulis yang disiapkan oleh wirausaha yang menggambarkan semua unsur-unsur yang relevan baik internal maupun eksternal mengenai perusahaan untuk memulai usaha baru. Isinya sering merupakan perencanaan terpadu menyangkut pemasaran, permodalan, manufaktur dan sumber daya manusia. (Peters dalam alma , 2017)

Bekerja Keras Sehingga Memiliki Sikap Berani Gagal Dalam Memulai Usaha

Terdapat $91 \%$ mahasiswa yang memiliki usaha pernah mengalami kegagalan dalam berbisnis, kegagalan ini telah memberikan pengalaman untuk perbaikan pada bisnis selanjutnya. Hal ini menunjukkan sikap kerja keras untuk mencapai keberhasilan. Seperti diungkapkan oleh mahasiswa Ahmad Sufaul chiqmah 20 tahun," Pernah gagal berbisnis, tapi saya coba lagi bisnis lainya, alhamdulillah jadi lebih paham dan berhati-hati agar tidak 
gagal lagi." dan dikatakan mahasiswa Diqqi Fajrudin Arridho 19 tahun, "Usaha saya banyak rugi sering... pengalaman rugi bisa jadi pengingat kalau bisnis lagi jangan lakukan kesalahan yang sama".

Menurut Zimmerer (dalam Suryana,2001), mengemukakan beberapa faktor-faktor yang menyebabkan wirausaha gagal dalam menjalankan usaha barunya yaitu : 1) tidak kompeten dalam manajerial. 2) kurang berpengalaman 3) kurang dapat mengendalikan keuangan. 4) gagal dalam perencanaan. 5) lokasi yang kurang memadai. ; 6) kurangnya pengawasan peralatan. 7) sikap yang kurang sungguh-sungguh dalam berusaha. 8) ketidakmampuan dalam melakukan peralihan/transisi kewirausahaan

Memiliki Pengetahuan \& Keterampilan Ditunjukkan Dengan Pernah Mengikuti Pelatihan Kewirausahaan

Seluruh mahasiswa yang telah memiliki usaha, selalu bersemangat bila diajak mengikuti pelatihan atau kuliah kewirausahaan. Pentingnya pelatihan kewirausahaan diungkapkan oleh mahasiswa Ahmad Rafi firdaus 22 tahun," Saya antusias bila mengikuti pelatihan kewirausahaan atau mengikuti pelajaran-pelajaran tentang kewirausahaan di kampus, karena selalu mampu memberikan motivasi dan pengetahuan tambahan yang penting bagi saya kedepan." dan dikatakan mahasiswa Agung Julio Nugroho 19 tahun,"Banyak hal yang saya dapatkan dari para pengusaha berpengalaman atau para dosen pembimbing tentang bagaimana melakukan usaha yang jitu bila saya ikut pelatihan atau pelajaran kewirausahaan."

Menurut Hendarwan, Pendidikan dan pelatihan kewirausahaan ini merupakan langkah serius dari pemerintah untuk mengatasi pengangguran terdidik yang terus bertambah jumlahnya. Ciputra (dalam Direktorat Kelembagaan Dikti, 2009) menegaskan bahwa pendidikan kewirausahaan bisa memberi dampak yang baik bagi masa depan Indonesia, seperti yang terjadi di Singapura. Namun kuncinya, pendidikan harus dijalankan dengan kreatif. Sejalan dengan itu praktik kewirausahaan akan memberikan kontribusi moral dan material kepada pelaku usaha.( Setiawan, H.C.B., 2019)

Dukungan Keluarga \& Lingkungan Kampus

Dari penelitian menunjukkan orang tua mahasiswa sebesar $74 \%$ adalah pengusaha dan $\quad 100 \%$ mahasiswa didukung keluarganya untuk berwirausaha.

Seperti diungkapkan oleh mahasiswa Nurus Sa'adah 21 tahun," Orang tua saya mempunyai usaha dirumah, beliau sangat mendukung saya untuk menjadi pengusaha." dan dikatakan mahasiswa Riza Fajriani 20 tahun, "Kedua orang tua dosen dan pegawai, namun belaiu berdua sangat support bila saya mantab membuka usaha."

Periera, Mashabi dan Muhariati (2017) mengungkapkan bahwa dukungan dalam keluarga dapat secara emosional, pemberian informasi-informasi yang berguna, pemberian penghargaan dan dukungan instrumental atau finansial. Melalui dukungan-dukungan yang diberikan keluarga, akan memberikan perasaan nyaman dan perasaan bahwa anggota keluarga saling mempedulikan satu dengan yang lainnya. Penelitian yang dilakukan oleh Periera et al. (2017) mengungkapkan bahwa dukungan keluarga dapat menentukan tinggi rendahnya niat individu dalam melakukan wirausaha. Individu yang memiliki niat untuk berwirausaha, pasti memerlukan restu dan dukungan dari keluarga sebagai kekuatan, keberanian dan penyemangat untuk melaksanakannya. Lingkungan kampus mendorong tumbuhnya pengusaha muda, dijelaskan selanjutnya dibawah ini.

\section{Peranan Inkubator Bisnis}

Peran Universitas diantaranya melalui pembuatan Laboratorium Kewirausahaan dan Pusat Inkubasi Bisnis yang bertujuan untuk mendorong agar mahasiswa memiliki bisnis sendiri yang lestari. Berikut penuturan Ketua Laboratorium dan Pusat Inkubasi Bisnis Bu Vembri 34 Tahun," Kita memberikan layanan kepada mahasiswa berupa tempat untuk mengembangkan usaha pada tahap awal, pembangunan keterampilan kewirausahaan diantaranya menyediakan peralatan untuk menciptakan produk baru... tempat konsultasi bisnis, memberikan dukungan kemudahan akses penelitian.. networking.. teknologi dan terkait 
investasi".

Kepala Program Studi kewirausahaan Pak Aries 43 tahun juga berkata , " Kita telah siapkan tempat praktek membuat produk baru, membekali keterampilan, pengetahuan dan mentalitas pengusaha melalui penugasan ke pasar atau sentrasentra bisnis. Kami juga dukung dana bergulir, yang bisa digunakan bergantian sebagai modal awal. Meski jumlahnya tidak besar namun bisa mengawali usaha."

" Program kami kedepan sedang merencanakan fasilitas kantor bersama semacam vitual office, sehingga seluruh mahasiswa yang memiliki usaha bisa menjadikanya sebagai representatif office untuk memulai usahanya. Setelah usaha mereka bisa mengumpul dalam satu kantor bersama akan kita dorong supaya bisa saling bekerjasama menumbuhkan sinergi dan kita carikan partner dnegan wirausahawan yang lebih berpengalaman agar mereka naik kelas dalam berbisnis." Lanjut pak Aries tentang rencana kedepan Prodi Kewirausahaan.

Lembaga dikatakan sebagai inkubator bisnis apabila menyediakan tujuh layanan inkubator kepada pemilik usaha sebagai berikut space, Shared, Services, Support, Skill development, Seed capital, dan Synergy (Bank Indonesia, 2006). Dalam hal ini sudah banyak yang dilakukan Universitas untuk memacu terciptanya Wirausahawan muda di kampus, namun sebagai inkubator bisnis masih belum optimal dalam hal Shared yakni belum menyediakan fasilitas kantor yang bisa digunakan secara bersama misalnya resepsionis, ruang konferensi, sistem telepon, faksimile, komputer, \& keamanan dan Synergy, yaitu belum tercipta kerjasama tenant atau persaingan antar tenant dan jejaring (network) dengan pihak universitas, lembaga riset, usaha swasta, professional maupun dengan masyarakat internasional.

\section{Mahasiswa dan Kewirausahaan}

Hasil penelitian diketahui bahwa setidaknya ada 8 bidang usaha yang ditekuni oleh mahasiswa, sesuai dengan diagram pie berikut:

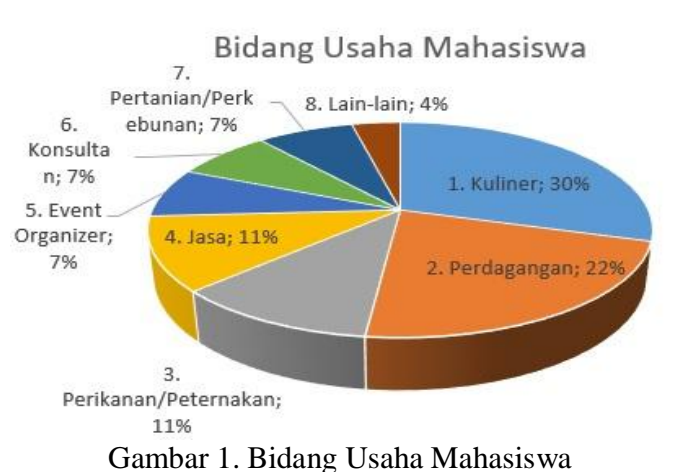

Diqqi Fajrudin Arridho 19 tahun, mengatakan "Saya sudah memiliki beberapa bisnis, bisnis yang paling menyita perhatian saya saat ini budidaya ikan Sidat,kerjasama dengan kakak alumni kampus ini." Dosen Heri Cahyo Bagus Setiawan 32 tahun mengatakan, “ Saat ini bisnis mahasiswa ada pada bidang kuliner, perdagangan dan perikanan. Era revolusi industri 4.0 harusnya ekonomi kreatif jadi modal persaingan... kuncinya ya terus melakukan inovasi dan kreativitas guna meningkatkan nilai tambah ekonomi di Amerika muncul gelombang ekonomi baru berupa karena barang dan jasa berbasis kreatifitas. Jadi mahasiswa perlu didorong ke bidang industri kreatif."

Ekonomi kreatif didefinisikan sebagai aktivitas ekonomi yang bertumpu pada eksplorasi dan eksploitasi ide-ide kreatif yang memiliki nilai jual tinggi. kita lihat hal ini pada 16 sektornya antara lain fesyen, seni, kuliner, desain produk, game on line, film, animasi, dan lainnya layak menjadi pilihan strategi untuk terus ditumbuhkembangkan. (John Howkins dalam Sugiarto,2018).

Sekarang ini mahasiswa semakin takut dengan berkurangnya kesempatan kerja yang tersedia sehingga mendorong untuk belajar kewirausahaan. Namun untuk membuka usaha ada beberapa kendala yang dihadapi mahasiswa berdasarkan penelitian adalah sebagai berikut :

\begin{tabular}{|l|l|c|}
\hline No & \multicolumn{1}{|c|}{ Kendala } & \% \\
\hline 1 & $\begin{array}{l}\text { Kurang Percaya Diri \& Mental } \\
\text { Pengusaha Belum Terbentuk }\end{array}$ & $50 \%$ \\
\hline 2 & $\begin{array}{l}\text { Tidak Bisa Membagi Waktu } \\
\text { Antara Kuliah Dan Usaha }\end{array}$ & $27 \%$ \\
\hline 3 & Masalah Modal \& Takut Resiko & $23 \%$ \\
\hline \multicolumn{2}{|l|}{ Tabel 1. Kendala Usaha Mahasiswa } \\
\hline
\end{tabular}

Kendala ini sejalan dengan apa yang disampaikan Thomas W.Zimmerer, 2001 bahwa dalam kewirausahaan akan muncul kendala yang akan dihadapi oleh setiap wirausaha . Oleh karena itu wirausaha harus mengantisipasi kendala yang dapat muncul 
seperti ketidakpastian pendapatan, resiko kehilangan seluruh investasi, kerja lama \& kerja keras, kualitas hidup rendah sampai bisnis mapan, tingkat stres tinggi, tanggung jawab penuh dan putus asa.

Kewirausahaan sendiri harus dipelajari dan di praktekkan terus-menerus sebagai sebuah proses membentuk mentalitas pengusaha, pengetahuan dan keterampilan secara bersamaan. Sesuai pernyataan Pak Aries (42 Tahun) Kaprodi Kewirausahaan, "Kurikulum Prodi Kewirausahaan telah dirancang berdasarkan relevansinya dengan tujuan, yakni lulusan yang memiliki wirausaha dilandasi akhlak mulia, unggul, profesional, berdaya saing, dan berkemandirian, cakupan dan kedalaman materi, pengorganisasian yang mendorong terbentuknya hard skills dan soft skills yang diterapkan dalam berbagai situasi dan kondisi."

Pertama kewirausahaan itu adalah proses, dan kedua kewirausahaan itu bukanlah suatu kegiatan yang berdiri sendiri melainkan suatu kegiatan berlanjut terus menerus. Jadi universitas perlu mempertimbangkan banyak hal mengenai proses pembelajaran yang berlangsung baik dalam kurikulum maupun metode pembelajaran sehingga mahasiswa mengalami proses dalam mendapatkan pengalaman yang bermakna dan proses tersebut dapat berlanjut pada saat menjalankan bisnis. (Stevenson dan Jarillo,1990).

\section{KESIMPULAN}

Dapat disimpulkan dari hasil penelitian adalah sebagai berikut :

1. Keberhasilan mahasiswa harus diikuti minat \& motivasi yang kuat, memiliki usaha sendiri, mampu membuat perencanaan usaha, bekerja keras, sehingga memiliki sikap berani gagal dalam memulai usaha, memiliki pengetahuan\& keterampilan ditunjukkan dengan pernah mengikuti pelatihan kewirausahaan dan adanya dukungan keluarga \& lingkungan kampus.

2. Universitas berperan memacu terciptanya wirausahawan muda di kampus, diantaranya memberikan layanan tempat pengembangan produk awal, peningkatan mutu usaha, memberikan pelatihan peningkatan keterampilan, pendampingan dan memberikan akses modal .

3. Inkubator bisnis di universitas masih belum optimal dalam hal shared, yakni belum menyediakan fasilitas kantor yang bisa digunakan secara bersama dan synergy, yaitu belum tercipta kerjasama tenant atau persaingan antar tenant dan jejaring (network) dengan pihak universitas, lembaga riset, usaha swasta, professional maupun dengan masyarakat internasional.

4. Kewirausahaan bukan kegiatan berdiri sendiri yang selesai ketika telah memiliki bisnis sendiri, tetapi kewirausahaan harus terus dipelajari dan di praktekkan sebagai sebuah proses membentuk mentalitas pengusaha, pengetahuan dan keterampilan secara bersamaan karena kehidupan dan bisnis selalu berkembang.

\section{SARAN}

Penelitian ini diberi saran :

1. Perlu dilakukan pembinaan kepada mahasiswa disertai dengan pengembangan kurikulum agar lebih dari $80 \%$ mahasiswa berhasil memiliki bisnis sendiri sejak kuliah.

2. Universitas melakukan upaya untuk penyempurnaan fasilitas sebagai inkubator bisnis, sehingga makin banyak lagi wirausahawan muda yang berhasil ditumbuhkan di kampus.

3. Perlu upaya agar mahasiswa memilih bisang usaha ekonomi kreatif, seperti bidang fesyen, seni, kuliner, desain produk, game on line, film, animasi, dan lainnya layak menjadi pilihan yang dikembangkan oleh mahasiwa, disamping bidang lain yang digemari saat ini.

4. Penelitian selanjutnya diarahkan kepada bagaimana Mahasiswa bisa sukses mengembangkan bisnis di sektor ekonomi kreatif. 


\section{DAFTAR PUSTAKA}

Ahmed, Ishfaq, et all. (2012), Do external factors influence students entrepreneurial inclination? an evidence based approach.Entrepreneurship journal, 978-953-51-0210-6, Intech, Marc 2012

Akmaliah, Z., dan H. Hisyamuddin, (2009),"Choice of Self-Employment Intentions Among Secondary School Studens", The Journal of International Social Research, Vol 2(9), pp.539-549.

Bank Indonesia. (2006). Kajian Inkubator Bisnis dalam Rangka Pengembangan UMKM.

Buchari, Alma. "Pengantar Bisnis." Edisi Revisi, cetakan kesembilan. Bandung: Alfabeta (2007).

Budiyanto, H., Suprapto, A., \& Poerwoningsih, D. (2017). Program Pengembangan Kewirausahaan dalam Bentuk Inkubator Bisnis Di perguruan Tinggi Bagi Mahasiswa Pemilik Usaha Pemula. SENASIF 2017 (hal. 385-394). UNMER Malang.

Direktorat Kelembagaan Dikti. 2009. Pedoman Program Mahasiswa Wirausaha Bagi Kopertis dan PTS.

Komara, B.D. and Prasetya, A., 2019. Konstruksi Sosial pada Pedagang Tradisional dalam Menghadapi Era Kompetisi Perdagangan Bebas. Jurnal Riset Entrepreneurship, 2(1), pp.1-8.

Komara, B.D. and Kurniawan, A., 2020. CHAPTER-04 "Solve the Problem for Student Entrepreneurship", 2(1), pp.1-8.

Kurniawan, A. and Asharudin, M., 2018. Small And Medium Enterprises (Smes) Face Digital Marketing. Muhammadiyah International Journal of Economics and Business, 1(2), pp.115-120.

Lose, T., \& Tengeh, R. K. (2015). The Sustainability and Challenges of Business of Business Incubators inthe Western Cape Province, South Africa. Journal of Sustainability,7,1434414357.

Loue, C., \& Baronet, J. (2012). Toward a new entrepreneurial skills and competencies framework: a qualitative and quantitative study. Int J Entrepreneurship and Small
Business , 14, 455-477.

Periera, A., Mashabi, N. A., \& Muhariati, M. (2017). Pengaruh dukungan orangtua terhadap minat anak dalam berwirausaha (pada siswa SMK Strada Koja, Jakarta Utara). Jurnal Kesejahteraan Keluarga dan Pendidikan, 4(2), 70-76.

Suryana. 2001. Kewirausahaan. Edisi Pertama. Jakarta: Salemba Empat.

Sugiarto, Eddy Cahyono.2018, Ekonomi Kreatif Masa Depan Indonesia. https://www.setneg.go.id/baca/index/ ekonomi_kreatif_masa_depan_indone sia

Prasetya, A. and Komara, B.D., 2019. Perlawanan Pedagang Kaki Lima Terhadap Kebijakan Relokasi Pemerintah Daerah. Jurnal Riset Entrepreneurship, 2(2), pp.1-7.

Setiawan, H.C.B., 2019. Kontribusi Praktik Kewirausahaan Di Pondok Pesantren (Studi Pada Pondok Pesantren Entrepreneur Mukmin Mandiri, Waru Sidoarjo). Jurnal Riset Entrepreneurship, 2(2), pp.8-18.

Scarborough,M.Norman \& Zimmerer, W Thomas.2002.PengantarKewirausaha an dan Manajemen Bisnis Kecil. Prenhallindo: Edisi Bahasa Indonesia.

Stevenson,H.H and Jarillo, J.C. 1990. A paradigm of entrepreneurship: entrepreneurialmanagement. Strategic Management Journal, Vol 11,17-27.

Tri Ispranoto - detikNews. 2017, Menpora: Indonesia Kekurangan Pengusaha Muda. dapat diakses di https://news.detik.com/berita-jawabarat/d-3576044/menpora-indonesiakekurangan-pengusaha-muda

Venesaar, U., Kolbre, E., and Piliste, T. (2006),'Students' Attitudes and Intentions toward Entrepreneurship at Tallinn University of Technology", TUTWPE Working Papers, No 154, pp.97-114. 